Vol 10, Issue 11, 2017

\title{
FORMULATION AND EVALUATION OF ISORHAMNETIN LOADED POLY LACTIC-CO-GLYCOLIC ACID NANOPARTICLES
}

\section{KANDAKUMAR SETTU, MANJU VAIYAPURI*}

\author{
Department of Biochemistry, Periyar University, Salem, Tamil Nadu, India. Email: manjucb11@gmail.com
}

Received: 15 May 2017, Revised and Accepted: 10 July 2017

ABSTRACT

Objective: The aim of the present study was formulation and evaluation of isorhamnetin loaded poly lactic-co-glycolic acid (PLGA) polymeric nanoparticles (NPs).

Methods: The present study was designed to incorporate the isorhamnetin in PLGA formulation by double emulsion solvent evaporation method, which offers a dynamic and flexible technology for enhancing drug solubility due to their biphasic characteristic, variety in design, composition and assembly. Synthesized isorhamnetin-PLGA NPs were characterized by Fourier transform infrared spectroscopy (FTIR), scanning electron microscopy (SEM), and particle size analyzer. We tested the efficacy of isorhamnetin-PLGA NPs in HepG2 cell lines.

Results: From the FTIR result, we concluded that -C-N-, -C=C-, N-H, C-N, N-O, O-H, and C-H are the functional groups present in isorhamnetin-PLGA NPs, SEM image shows spherical shape of particles. The particle size analysis result shows 255-342 nm range of particles. Isorhamnetin-PLGA NPs significantly enhanced $(\mathrm{p}<0.05)$ the antiproliferative effect when compared to the plain drug.

Conclusion: This study concluded that the newly formulated NP drug delivery systems of isorhamnetin provided an insight into the therapeutic effectiveness of the designed formulation for the treatment of chemotherapy.

Keywords: Isorhamnetin, Poly lactic-co-glycolic acid, W/O/W emulsion, Antiproliferative activity, HepG2.

(C) 2017 The Authors. Published by Innovare Academic Sciences Pvt Ltd. This is an open access article under the CC BY license (http://creativecommons. org/licenses/by/4. 0/) DOI: http://dx.doi.org/10.22159/ajpcr.2017.v10i11.19918.

\section{INTRODUCTION}

The polymeric nanoparticles (NPs) are prepared from biocompatible and biodegradable polymers in size between 10 and $1000 \mathrm{~nm}$ where the drug is dissolved, entrapped, encapsulated, or attached to a NP surrounding substance. Depending on the way of preparation NPs, nanospheres or nanocapsules can be obtained. Nanocapsules are systems in which the drug is confined to a hollow space surrounded by a single polymer membrane, while nanospheres are matrix systems in which the drug is physically and uniformly dispersed [1-3]. Recent drug carrier systems play a key role in controlled discharge of a pharmaceutical mediator to the target at a therapeutically best possible rate and dose efficacy, reduced side effects, incessant dosing, reduced ache from administration, increased ease of use and improved mobility [4]. Drug delivery vehicles based on polymeric NPs have shown huge potential in terms of cellular uptake, overcoming drug resistance by modulation or reversion of P-glycoprotein activity, controlled drug delivery, and prolonged efficacy $[5,6]$. In many cases, NPs accumulate on the cell membrane and are mainly internalized by endocytosis [7].

Poly lactic-co-glycolic acid (PLGA), a Food and Drug Administrationapproved biocompatible and biodegradable polymer, has been widely used to carry chemotherapy drugs, nucleic acids and proteins for cancer therapy [8-10]. PLGA NPs are colloidal polymeric drug carriers that grasp promise for peroral drug delivery which represents by far the most general and suitable way of administration. This PLGA-NPs offer a lot of advantages in excess of conventional oral dosage forms, such as enhancing the oral bioavailability of those poorly absorbed drugs, protecting the encapsulated drugs in the polymer system [11,12].

Numerous encapsulation techniques have already been developed to prepare particulate sustained drug release systems, some of the commonly reported methods of preparing NPs from biodegradable polymers include emulsion solvent evaporation [13], monomer polymerization [14], nanoprecipitation [15], cross-flow filtration [16] or emulsion-diffusion technique [17], and the salting out method. However, the selection of a particular technique of encapsulation is typically determined by the solubility characteristics of the drug [18]. At present, an enormous range of synthetic and herbal drugs, biological enzymes, minute hydrophilic and hydrophobic drugs, vaccines, and macromolecules can be loaded or encapsulated in the NPs by double emulsion solvent evaporation technique, for efficient delivery [19-22].

The flavonoid isorhamnetin also called as $3^{\prime}$-methoxy-3, 4', 5, 7-tetrahydroxyflavone (Fig. 1) is the metabolite of quercetin, and it is naturally occurring 0 -methylated flavonol that is rich in apples, blackberries, cherries, and pears [23-25]. Recent studies have shown that isorhamnetin exerts anticancer property, particularly inhibits the proliferation of numerous cancer cell lines and suppresses the weight and size of tumors of Lewis lung carcinoma cell allografts in mice [26-28].<smiles>COc1cc(-c2oc3cc(O)cc(O)c3c(=O)c2O)ccc1O</smiles>

Fig. 1: Isorhamnetin 
This study provides an improved method for producing isorhamnetin loaded PLGA NPs (IR-PLGA NPs) with the following objectives: (i) Preparation of IR-PLGA NPs. (ii) Characterization of the prepared IRPLGA NPs by FTIR, SEM, particle size analyzer (PSA), and cytotoxicity assay.

\section{METHODS}

\section{Chemicals}

Poly (DL-lactide-co-glycolide) (PLGA-50:50), with a molecular weight of 76,000-115,000, isorhamnetin $\left(\mathrm{C}_{16} \mathrm{H}_{12} \mathrm{O}_{7}\right)$ with a molecular weight of 316.26 were purchased from Sigma Chemical Co. (St. Louis, MO, USA). Dulbecco's modified eagle's medium (DMEM), 3-(4, 5-dimethylthiazol2-yl)-2,5-diphenyl tetrazolium bromide (MTT), and fetal bovine serum (FBS), were procured from Sigma-Aldrich (St. Louis, MO, USA). Dimethyl sulfoxide (DMSO), dichloromethane and acetone, polyvinyl alcohol (PVA), PBS buffer chemicals ( $\mathrm{NaCl}, \mathrm{KCl}, \mathrm{Na}_{2} \mathrm{HPO}_{4} \mathrm{KH}_{2} \mathrm{PO}_{4}$, and HCL) were purchased from HiMedia Chemicals Pvt. Lim. India. All other chemicals and reagents used were of analytical grade.

\section{Cell culture and treatment}

Hepatocellular carcinoma cell line (HepG2) was obtained from National Centre for Cell Science Pune. Cells were cultured and maintained in DMEM medium, supplemented with $10 \%$ (v/v) FBS and $1 \%(\mathrm{v} / \mathrm{v})$ penicillin/streptomycin $(100,000 \mathrm{U} / \mathrm{l}$ penicillin, $100 \mathrm{mg} / \mathrm{l}$ streptomycin), at $37^{\circ} \mathrm{C}$ in a humidified atmosphere containing $5 \%$ carbon dioxide and $95 \%$ room air.

\section{Formulation of isorhamnetin loaded PLGA NPs}

Isorhamnetin loaded PLGA NPs (IR-PLGA NPs) were prepared by double emulsion solvent evaporation method $[15,29]$. This technique has two phases in the name of organic and in organic. In organic phase, $0.25 \mathrm{~g}$ of PLGA (50:50) polymer was taken in $10 \mathrm{ml}$ of mixture of dichloromethane and acetone $(85: 15, \mathrm{v} / \mathrm{v})$ in internal aqueous phase (IAP). $25 \mathrm{mg}$ of isorhamnetin ( $10 \%$ dry weight of polymer) was dissolved in $40 \mathrm{ml}$ of PBS (67 mM, pH 6.0). The two solutions were mixed by ultrasonication for 1 minute under cooling to form W1/O emulsion that is so called inner emulsion. The inner emulsion stabilizer was slowly added to $100 \mathrm{ml}$ of $1 \%(\mathrm{w} / \mathrm{v})$ aqueous PVA solution which was homogenized with a high-speed mixture for 8 min at $8500 \mathrm{rpm}$. The resulting W1/0/W2 emulsion was stirred at $300 \mathrm{rpm}$ over night to maximum evaporation of organic solvent. Then, the sample was washed 3 times with Milli-Q water at $12000 \mathrm{rpm}$ for 15 minutes then particles were formed. These particles were allowed to lyophilization for fine particles and preserved for further analysis.

\section{Compatibility study - By Fourier transform infrared spectroscopy (FTIR) \\ FTIR}

IR spectra of isorhamnetin and other excipients used in the formulation were recorded using "Perkin-Elmer FTIR." The sample for the IR spectroscopy was prepared by mixing the IR-PLGA NPs with spectroscopic grade $\mathrm{KBr}$ and compressed into transparent pellets, then scanned in the IR range from $500-4000 / \mathrm{cm}$ with a resolution of $4 / \mathrm{cm}[30]$.

\section{Morphology study}

Scanning electron microscope (SEM)

The morphology of IR-PLGA NPs was examined by scanning electron microscopy (SEM, VEGA 3 TESCAN). The IR-PLGA NPs were mounted on metal stubs using double-sided tape and coated with a $150 \AA$ layer of gold under vacuum. Stubs were visualized under scanning electron microscope [31].

\section{Determination of particle size}

The particle size and size distribution of the IR loaded PLGA (50:50) NPs were characterized by laser light scattering using particle size analyzer (Malvern Mastersizer Hydro-2000 SM, UK). The obscuration level was set between 7 and 11\%; distilled water was used as a medium.
Cytotoxicity study by MTT assay

The cytotoxicity of IR and IR-PLGA NPs were determined by the MTT assay $[32,33]$. Briefly, $5 \times 10^{3}$ cells/well was plated in 96-well tissue culture plates. IR and freeze-dried IR-PLGA NPs were diluted in culture media and $100 \mu \mathrm{l}$ of different concentrations added to wells. IR solution was replaced after every 24 hrs for 3 days while IR-PLGA NPs were added once. After $72 \mathrm{hrs,} \mathrm{the} \mathrm{supernatant} \mathrm{was} \mathrm{flicked} \mathrm{off,}$ $50 \mu \mathrm{l}$ of MTT $(0.5 \mathrm{mg} / \mathrm{mL})$ added to each well and incubated for 4 hrs. The unreduced MTT and medium were then discarded. Each well was washed with $200 \mu \mathrm{l}$ of PBS. $200 \mu \mathrm{l}$ of DMSO was added to each well to dissolve the MTT formazan crystals. Plates were shaken for 20 minutes, and absorbance was measured at $540 \mathrm{~nm}$ using the microplate reader (Bio-Tek, ELX-800 MS) [34]. The $\mathrm{IC}_{50}$ values were calculated from concentration-effect curves, considering the optical density of the control well as $100 \%$. The experiments were repeated 5 times.

\section{Statistical analysis}

Data are represented as mean \pm standard deviation of four readings.

\section{RESULTS AND DISCUSSION}

FTIR

FT-IR was carried out to identify the functional groups present in IR-PLGA NPs (Fig. 2). The absorption bands at above 3351/cm may be responsible for the presence of $\mathrm{O}-\mathrm{H}$ and $\mathrm{N}-\mathrm{H}$ stretching vibrations. Bands at $2802 / \mathrm{cm}, 2383 / \mathrm{cm}$ are due to $\mathrm{C}-\mathrm{H}$ stretching vibration. A band at $1584 / \mathrm{cm}$ showed the presence of $-\mathrm{C}=\mathrm{C}$ - groups. A band at $1487 / \mathrm{cm}$ and $1300 / \mathrm{cm}$ is characteristic stretching vibration of $\mathrm{N}-\mathrm{O}$. A band at $1449 / \mathrm{cm}$ shows the presence of C-C stretching vibration of aromatics. Bands at $1188 / \mathrm{cmand} 1046 / \mathrm{cm}$ may be attributed to the presence of $\mathrm{C}-\mathrm{N}$ aliphatic amines. A band at $890 / \mathrm{cm}$ indicates the presence of $\mathrm{O}-\mathrm{H}$ bend. $689 / \mathrm{cm}$ and $534 / \mathrm{cm}$ bands showed the presence of $\mathrm{C}-\mathrm{Cl}$ and $\mathrm{C}$-Br stretching vibrations of alkyl halides. The obtained peak values and their respective functional groups of IR-PLGA NPs were shown in Table 1. From the FT-IR results, we concluded that $-\mathrm{C}-\mathrm{N}-,-\mathrm{C}=\mathrm{C}-, \mathrm{N}-\mathrm{H}$, $\mathrm{C}-\mathrm{N}, \mathrm{N}-\mathrm{O}, \mathrm{O}-\mathrm{H}, \mathrm{C}-\mathrm{Cl}, \mathrm{C}-\mathrm{Br}$, and $\mathrm{C}-\mathrm{H}$ are the functional groups present in IR-PLGA NPs. Previously, FTIR analysis was also performed by other investigators to characterize this type of interactions between drugs and PLGA polymer [35-37].

\section{SEM}

The obtained SEM image of the encapsulated isorhamnetin with PLGA NPs was shown in Fig. 3. The IR-PLGA NPs are well dispersed. The morphology of IR-PLGA NPs was nanometric size and spherical in shape. The surface of the particles are smooth and rounded that possesses pores of varying size. However, the rough surface of polymeric NPs could be owing to the lack of sonication during the preparation of NPs. It was reported that, if the ratio of the IAP to external aqueous phase was increased, the relative sizes of the pores also tends to increase [38].

Table 1: Obtained peaks and their corresponding functional groups in IR-PLGA NPs

\begin{tabular}{lll}
\hline Frequency $\left(\mathbf{c m}^{-\mathbf{1}}\right)$ & Bond & $\begin{array}{l}\text { Functional } \\
\text { group }\end{array}$ \\
\hline 3351.54 & O-H stretch, H-bonded & $\begin{array}{l}\text { Alcohols, phenols } \\
\text { Alkanes }\end{array}$ \\
$2802.00,2383.69$, & C-H stretch & \\
2250.49 & & Alkenes \\
1584.24 & -C=C- stretch & Nitro compounds \\
1487.41 & N-O asymmetric stretch & Aromatics \\
1449.46 & C-C stretch (in-ring) & Nitro compounds \\
1300.17 & N-O symmetric stretch & Aliphatic amines \\
$1188.64,1104.88$ & C-N stretch & Carboxylic acids \\
890.17 & O-H bend & Alkyl halides \\
689.56 & C-Cl stretch & Alkyl halides \\
534.07 & C-Br stretch &
\end{tabular}

IR-PLGA: Infrared-poly lactic-co-glycolic acid, NPs: Nanoparticles 


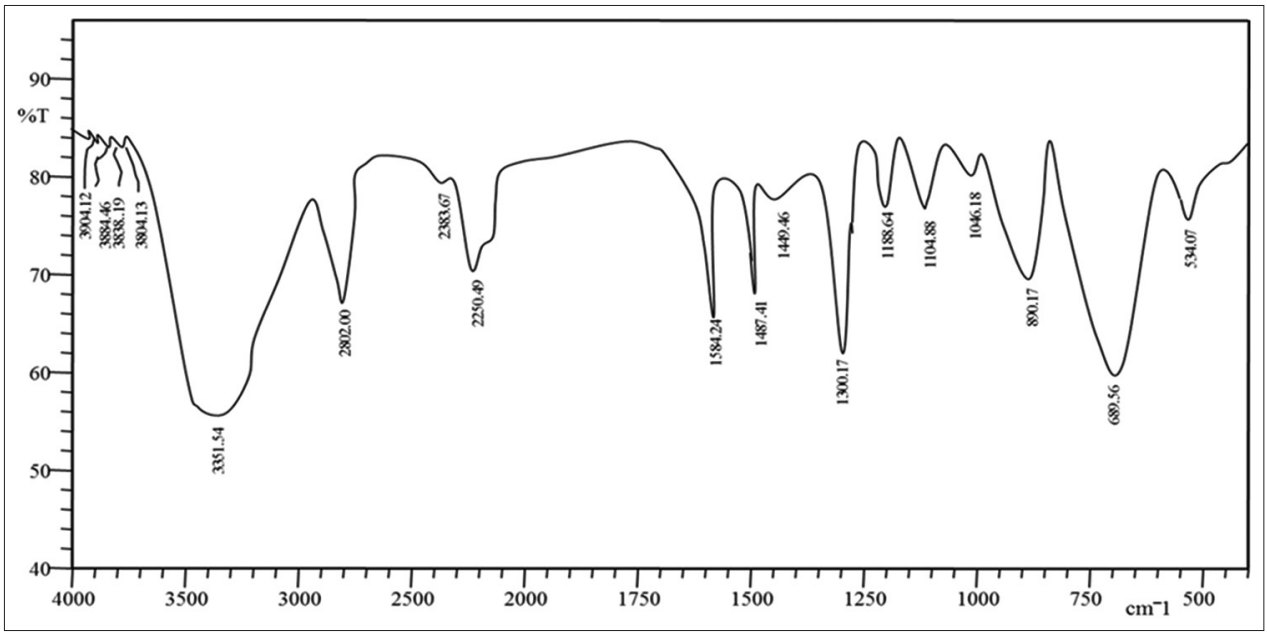

Fig. 2: Fourier transform infrared spectroscopy of infrared-poly lactic-co-glycolic acid nanoparticles

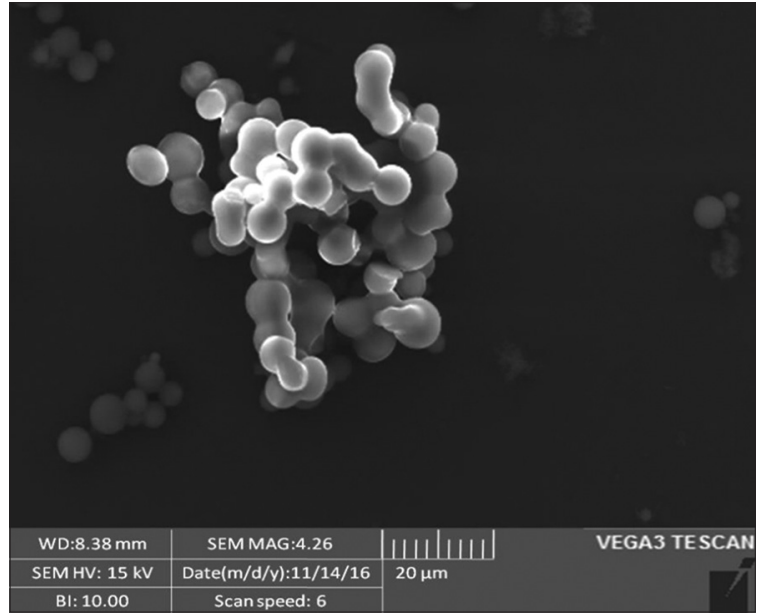

Fig. 3: Scanning electron microscopy image of infrared-poly lacticco-glycolic acid nanoparticles

PSA

The distribution of particle size was proportioned in good conformity with the result measured by particle size analyzer (Fig. 4a and b). The particle size analysis ranges from 255 to $342 \mathrm{~nm}$ which shows the highest peak for IR-PLGA NPs was found to be around $300 \mathrm{~nm}$. Specifically, intense peak was found at $297.4 \mathrm{~nm}$. Polymeric NPs of a size around or $<300 \mathrm{~nm}$ coated with surfactants have been proved to be able to transport drugs across the blood brain barrier [39]. The negative electric charge attributed on the surface of NPs is due to carboxylate end groups of PLGA [40]. Many factors are known to influence the particles size, one among them is the molecular weight of polymer. However, the increase in particles size can be obtained when we increase the molecular weight $(76,000-115,000 \mathrm{Da})$ of the polymer.

The promising reason could be the increase in viscosity of the polymer solution in the organic phase with increasing molecular weight poses resistance to break down the nanodroplets in a smaller size on the input of same energy [41]. Moreover, another study also stated similar results from the estradiol loaded PLGA NPs [42]. Slight increase in the encapsulation efficiency was observed with the increase in polymer molecular weight. Thus, the escape of drug molecules from denser polymer matrix becomes difficult; thereby the encapsulation efficiency increases in higher molecular weight polymer formulations [43]

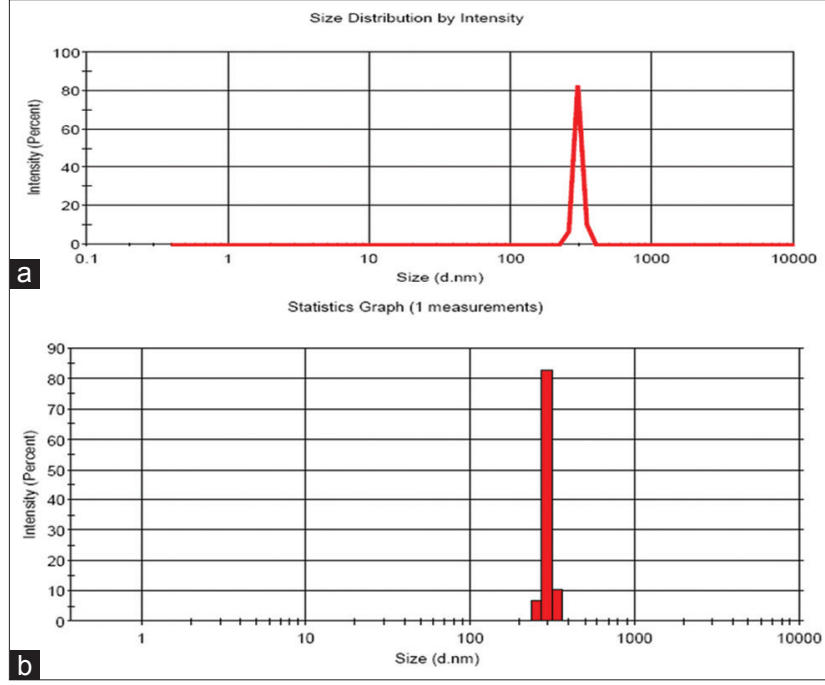

Fig. 4: (a) Particle size distribution, (b) particle size analysis by dynamic light scattering

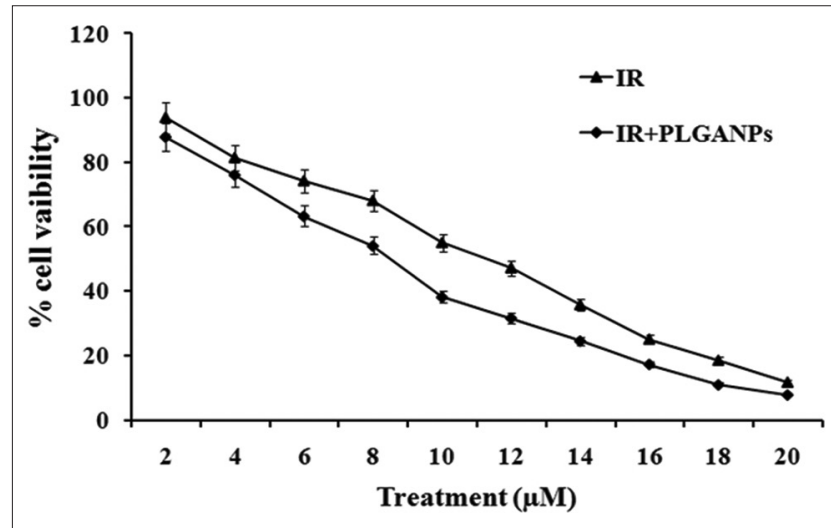

Fig. 5: Cytotoxic effect of infrared-poly lactic-co-glycolic acidnanoparticles against HepG2 cell line

Cytotoxicity studies of IR-PLGA NPs

The IR-PLGA-NPs were tested on liver cancer cells (HepG2). The cytotoxicity of IR-PLGA-NPs was significantly $(\mathrm{p}<0.05)$ higher $\left(\mathrm{IC}_{50}-8.5 \mu \mathrm{M}\right)$ than the plain drug $\left(\mathrm{IC}_{50}-11.2 \mu \mathrm{M}\right)$ in HepG2 cancer cells 
(Fig. 5). The IR-PLGA-NPs showed higher cytotoxicity when compared with the plain drug. The results clearly showed that the IR-PLGANPs had greater penetration leading to higher cytotoxic potential in cell cultures. Recently, numerous drug loaded PLGA NPs also has the tremendous cytotoxicity effects against many cancer cell lines, the prostate cancer cells LN-CaP, breast cancer cells MCF-7, and MDAMB-231 were effectively suppressed by the PLGA liposomes and NPs [44]. Similarly, at this point, HepG2 cells are efficiently suppressed by IR-PLGA-NPs compared with plain drug.

\section{CONCLUSION}

Conclusion drawn from the present study is that the NPs may be a suitable device for administration of isorhamnetin. From the results, - $\mathrm{C}$ $\mathrm{N}-,-\mathrm{C}=\mathrm{C}-, \mathrm{N}-\mathrm{H}, \mathrm{C}-\mathrm{N}, \mathrm{N}-\mathrm{O}, \mathrm{O}-\mathrm{H}$, and $\mathrm{C}-\mathrm{H}$ are the functional groups present in IR-PLGA NPs by FTIR; SEM image shows spherical shape of particles. The particle size analysis result shows $255-342 \mathrm{~nm}$ range of particles. Isorhamnetin-PLGA NPs significantly enhanced $(\mathrm{p}<0.05)$ the antiproliferative effect when compared to the plain drug. This encapsulation method was suitable for the preparation of drug NPs and development of a system whereby drugs could be administered and maintains the energetic levels of drug for a prolonged period would be the ideal system. Hence, this study concluded that the newly formulated NP drug delivery systems of isorhamnetin provided an insight into the therapeutic effectiveness of the designed formulation for the treatment of chemotherapy.

\section{REFERENCES}

1. Soppimath KS, Aminabhavi TM, Kulkarni AR, Rudzinski WE. Biodegradable polymeric nanoparticles as drug delivery devices. J Control Release 2001;70(1-2):1-20.

2. Mohanraj J, Chen Y. Nanoparticles - A review. Trop J Pharm Res 2006;5(1):561-73.

3. Rohit M, Showkat R, Saima A. Polymeric nanoparticles for improved bioavailability of cilnidipine. Int J Pharm Pharm Sci 2017;9(4):129-39.

4. Martin F, Grove C. Microfabricated drug delivery systems: Concepts to improve clinical. Biomed Micro 2001;3:97-108.

5. Alexis F, Pridgen E, Molnar LK, Farokhzad OC. Factors affecting the clearance and biodistribution of polymeric nanoparticles. Mol Pharm 2008;5(4):505-15.

6. Kini S, Bahadur D, Panda D. Mechanism of anti-cancer activity of benomyl loaded nanoparticles in multidrug resistant cancer cells. J Biomed Nanotechnol 2015;11(5):877-89.

7. Hu CM, Zhang L. Therapeutic nanoparticles to combat cancer drug resistance. Curr Drug Metab 2009;10(8):836-41.

8. Jain RA. The manufacturing techniques of various drug loaded biodegradable poly(lactide-co-glycolide) (PLGA) devices. Biomaterials 2000;21(23):2475-90.

9. Yoo HS, Lee KH, Oh JE, Park TG. In vitro and in vivo anti-tumor activities of nanoparticles based on doxorubicin-PLGA conjugates. J Control Release 2000;68(3):419-31.

10. Feng SS, Mu L, Win KY, Huang G. Nanoparticles of biodegradable polymers for clinical administration of paclitaxel. Curr Med Chem 2004;11(4):413-24.

11. Li X, Xu Y, Chen G, Wei P, Ping Q. PLGA nanoparticles for the oral delivery of 5-Fluorouracil using high pressure homogenizationemulsification as the preparation method and in vitro/in vivo studies. Drug Dev Ind Pharm 2008;34(1):107-15.

12. Rungsinee P, Wantida C, Songyot A. Curcumin-loaded multi-valent ligands conjugated-nanoparticles for anti-inflammatory activity. Int J Pharm Pharm Sci 2015;7(4):203-8.

13. Budhian A, Siegel SJ, Winey KI. Production of haloperidol-loaded PLGA nanoparticles for extended controlled drug release of haloperidol. J Microencapsul 2005;22(7):773-85.

14. Peng T, Cheng SX, Zhuo RX. Synthesis and characterization of polyalpha, beta-[N-(2-hydroxyethyl)-L-aspartamide]-g-poly(L-lactide) biodegradable copolymers as drug carriers. J Biomed Mater Res A 2006;76(1):163-73.

15. Govender T, Stolnik S, Garnett MC, Illum L, Davis SS. PLGA nanoparticles prepared by nanoprecipitation: Drug loading and release studies of a water soluble drug. J Control Release 1999;57(2):171-85.

16. Quintanar-Guerrero D, Ganem-Quintanar A, Allémann E, Fessi H,
Doelker E. Influence of the stabilizer coating layer on the purification and freeze-drying of poly(D,L-lactic acid) nanoparticles prepared by an emulsion-diffusion technique. J Microencapsul 1998;15(1):107-19.

17. Konan YN, Cerny R, Favet J, Berton M, Gurny R, Allémann E. Preparation and characterization of sterile sub-200 nm meso-tetra(4hydroxylphenyl)porphyrin-loaded nanoparticles for photodynamic therapy. Eur J Pharm Biopharm 2003;55(1):115-24.

18. Avgoustakis K. Pegylated poly(lactide) and poly(lactide-co-glycolide) nanoparticles: Preparation, properties and possible applications in drug delivery. Curr Drug Deliv 2004;1(4):321-33.

19. Makadia HK, Siegel SJ. Poly lactic-co-glycolic acid (PLGA) as biodegradable controlled drug delivery carrier. Polymers (Basel) 2011;3(3):1377-97.

20. Muller H, Petersen D, Hommoss A, Pardeike J. Nanostructured lipid carriers (NLC) in cosmetic dermal products. Adv Drug Deliv Rev 2007;59(6):522-30.

21. Wissing S, Müller R. The influence of the crystallinity of lipid nanoparticles on their occlusive properties. Int $\mathrm{J}$ Pharm 2002;242(1-2):377-9.

22. Schäfer-Korting M, Mehnert W, Korting HC. Lipid nanoparticles for improved topical application of drugs for skin diseases. Adv Drug Deliv Rev 2007;59(6):427-43

23. Pennington J. Food composition databases for bioactive food components. J Food Compost Anal 2002;15:419-34.

24. Saleh NA, Mansour RM, Markham KR. An acylated isorhamnetin glycoside from Aerva javanica. Phytochemistry 1990;29(4):1344-5.

25. Park JC, Young HS, Yu YB, Lee JH. Isorhamnetin sulphate from the leaves and stems of Oenanthe javanica in Korea. Planta Med 1995;61(4):377-8.

26. Ma G, Yang C, Qu Y, Wei H, Zhang T, Zhang N. The flavonoid component isorhamnetin in vitro inhibits proliferation and induces apoptosis in Eca-109 cells. Chem Biol Interact 2007;167(2):153-60.

27. Lee K, Kwon M, Baek I, Kim H, Lee H, Park H, et al. Ant proliferation effects of isorhamnetin isolated from Persicaria thunbergii on cancer cell lines. Nat Prod Sci 2006;12:214-26.

28. Steffen Y, Gruber C, Schewe T, Sies H. Mono-O-methylated flavanols and other flavonoids as inhibitors of endothelial NADPH oxidase. Arch Biochem Biophys 2008;469(2):209-19.

29. Rawat S, Malviya N, Motwani S. Smart biodegradable polymeric nanoparticles and their applications: A review. Indian Drugs 2008;45(8):601-5.

30. Kumari A, Yadav SK, Yadav SC. Biodegradable polymeric nanoparticles based drug delivery systems. Colloids Surf B Biointerfaces 2010;75(1):1-18

31. Grillo R, Pereira Ado E, de Melo NF, Porto RM, Feitosa LO, Tonello PS, et al. Controlled release system for ametryn using polymer microspheres: Preparation, characterization and release kinetics in water. J Hazard Mater 2011;186(2-3):1645-51

32. Osman E, Eid M, Khattab H, Mohmoud D. In vitro cytotoxicity of biosynthesized Ag/CS NP against MCF7, PC3 and A549 cancer cell lines. Int J Pharm Res 2015;8:1011-7.

33. Anggraeni R, Hadisahputra S, Silalahi J. Combinational effects of ethyl acetate extract of Zanthoxylum acanthopodium DC. With doxorubicin on T47D breast cancer cells. Int J Pharm Res 2015;7:2032-5.

34. Mosmann T. Rapid colorimetric assay for cellular growth and survival: Application to proliferation and cytotoxicity assays. J Immunol Methods 1983;65(1-2):55-63.

35. Dai WG, Dong LC, Song YQ. Nanosizing of a drug/carrageenan complex to increase solubility and dissolution rate. Int $\mathrm{J}$ Pharm 2007;342(1-2):201-7.

36. Amrutkar JR, Gattani SG. Chitosan-chondroitin sulfate based matrix tablets for colon specific delivery of indomethacin. AAPS PharmSciTech 2009;10(2):670-7.

37. Tiyaboonchai W, Limpeanchob N. Formulation and characterization of amphotericin B-chitosan-dextran sulfate nanoparticles. Int J Pharm 2007;329(1-2):142-9.

38. Nayak B, Panda AK, Ray P, Ray AR. Formulation, characterization and evaluation of rotavirus encapsulated PLA and PLGA particles for oral vaccination. J Microencapsul 2009;26(2):154-65.

39. Schroeder U, Sommerfeld P, Ulrich S, Sabel BA. Nanoparticle technology for delivery of drugs across the blood-brain barrier. J Pharm Sci 1998;87(11):1305-7.

40. Zambaux MF, Bonneaux F, Gref R, Maincent P, Dellacherie E, Alonso $\mathrm{MJ}$, et al. Influence of experimental parameters on the characteristics of poly(lactic acid) nanoparticles prepared by a double emulsion method. J Control Release 1998;50(1-3):31-40.

41. Surolia R, Pachauri M, Ghosh PC. Preparation and characterization 
of monensin loaded PLGA nanoparticles: In vitro anti-malarial activity against Plasmodium falciparum. J Biomed Nanotechnol 2012;8(1):172-81.

42. Bilati U, Allemann E, Doelker E. Poly (D, L-lactide-coglycolide) protein-loaded nanoparticles prepared by the double emulsion methodprocessing and formulation issues for enhanced entrapment efficiency. J Microencapsul 2005;22:205-214
43. Mundargi RC, Babu VR, Rangaswamy V, Patel P, Aminabhavi TM. Nano/micro technologies for delivering macromolecular therapeutics using poly(D,L-lactide-co-glycolide) and its derivatives. J Control Release 2008;125(3):193-209.

44. Prateek J, Mradul T, Nitesh K, Venkata R, Udupa N. Preparation and evaluation of decitabine loaded liposomes for effective chemotherapy. Int J Pharm Res 2016;9(9):208-13. 